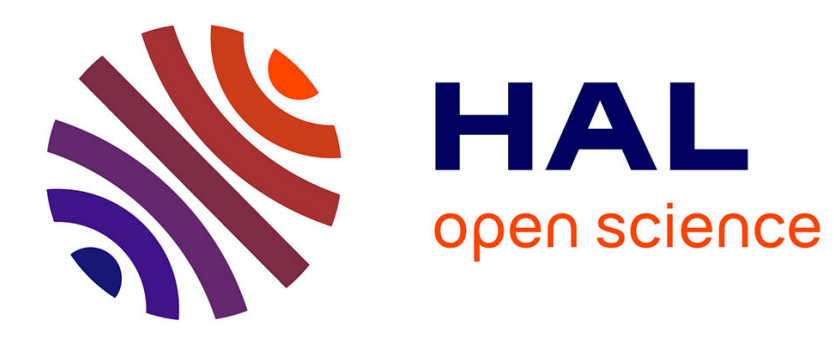

\title{
Morphometry of Middle Bronze Age palstaves by discrete cosine transform.
}

\author{
Benoît Forel, Maréva Gabillot, Fabrice Monna, S. Forel, Cyril Hugues \\ Dommergues, Sylvain Gerber, Christophe Petit, Claude Mordant, Carmela \\ Chateau
}

\section{To cite this version:}

Benoît Forel, Maréva Gabillot, Fabrice Monna, S. Forel, Cyril Hugues Dommergues, et al.. Morphometry of Middle Bronze Age palstaves by discrete cosine transform.. Journal of Archaeological Science, 2009, 36 (3), pp.721-729. 10.1016/j.jas.2008.10.021 . hal-00355053

\section{HAL Id: hal-00355053 https://hal.science/hal-00355053}

Submitted on 15 Jun 2020

HAL is a multi-disciplinary open access archive for the deposit and dissemination of scientific research documents, whether they are published or not. The documents may come from teaching and research institutions in France or abroad, or from public or private research centers.
L'archive ouverte pluridisciplinaire HAL, est destinée au dépôt et à la diffusion de documents scientifiques de niveau recherche, publiés ou non, émanant des établissements d'enseignement et de recherche français ou étrangers, des laboratoires publics ou privés. 


\title{
Morphometry of Middle Bronze Age palstaves by Discrete Cosine Transform
}

\author{
B. Forel ${ }^{\mathrm{a}, *}$, M. Gabillot ${ }^{\mathrm{a}}$, F. Monna ${ }^{\mathrm{a}}$, S. Forel $^{\mathrm{b}}$, C.H. Dommergues ${ }^{\mathrm{c}}$, S. Gerber ${ }^{\mathrm{c}}$, C. Petit ${ }^{\mathrm{a}}$, \\ C. Mordant ${ }^{\mathrm{a}}$, C. Chateau ${ }^{\mathrm{d}}$ \\ a ARTeHIS, UMR 5594, Université de Bourgogne, CNRS, Ministère de la Culture, 6 Bd Gabriel, bât. Sciences Gabriel, F-21000 Dijon, France \\ ${ }^{\mathrm{b}}$ Institut National de Recherches Archéologiques Préventives, Rente du Bassin, rue Aristide Berges, F-21800 Sennecey-les-Dijon, France \\ ${ }^{\mathrm{c}}$ Biogéosciences, UMR 5561, Université de Bourgogne, CNRS, 6 Bd Gabriel, bât. Sciences Gabriel, F-21000 Dijon, France \\ ${ }^{\mathrm{d}}$ Centre des Sciences de la Terre, Université de Bourgogne, 6 Bd Gabriel, bât. Sciences Gabriel, F-21000 Dijon, France
}

\section{A R T I C L E I N F O}

Article history:

Received 9 July 2008

Received in revised form

22 October 2008

Accepted 25 October 2008

\section{Keywords:}

Bronze axe

Morphology

Shape analysis

Typology

Open contour

\begin{abstract}
A B S T R A C T
The Discrete Cosine Transform (DCT) is a Fourier-related transform widely used in signal processing and well suited to the analysis of open outlines. This method was applied here to evaluate the discrimination power of the inner lateral rib for two palstave populations dating from the Middle Bronze Age, excavated in northwest France. A corpus of almost 400 palstaves (bronze axes) of the Breton and Norman types was processed, and compared to specimens found at Sermizelles in Burgundy. The procedure is robust and produces a discrimination in good agreement with the traditional typology. Besides the definition of a 'standard' shape for each population, the morphometrical approach allows shape disparity, which is generally inaccessible to the naked eye, to be visualised and quantified. Shape disparity indicates that, contrary to previous assumptions, the bronze axes from the Sermizelles hoards cannot be explained as an assortment of Breton and Norman palstaves alone. We believe that this approach is quick, reproducible, and generalisable enough to be applied to a wide variety of artefacts from different periods, in order to clarify their typology and even their origin. $\odot$
\end{abstract}

\section{Introduction}

Metal holds a key position among materials used during the European Bronze Age (2300-800 B.C.) because of its increasing predominance in prehistoric societies (Harding, 2000; Pare, 2000). The metallurgical chain covers all stages from the acquisition of the raw material to the circulation of the finished objects (e.g., Needham, 1998). However, these artefacts are generally the only remaining evidence of the chain. The Bronze Age is characterised by various associations of metallic objects buried together into the ground, which are called 'hoards'. Even if their interpretation is still subject to discussion (e.g., Gabillot and Gomez de Soto, 2007), the study of these metal artefacts allows the geographical and temporal extent of human cultures to be constrained, thus facilitating assessment of the relationships between them. The size, diversity and number of hoards increased greatly during the Middle Bronze Age $(1650-1350$ B.C.). This phenomenon is concomitant to considerable changes in metallurgical practices, especially the development of mass production (Briard and Bigot, 1989; Millotte, 1989; Mordant, 1998; Gabillot, 2003); some artefacts are known to have come from the same mould. Palstaves, in use daily as tools, are

\footnotetext{
* Corresponding author. Tel.: +33 3803963 60; fax: +33 380395787 E-mail address: benoit.forel@wanadoo.fr (B. Forel).
}

found abundantly in Western European hoards. They correspond to a technical improvement of Early Bronze Age (2300-1650 B.C.) flanged axes, as they allow better handle fixation. In France, two main types of palstaves have been defined by the French Prehistorical Society: the Breton and the Norman types (Briard and Verron, 1976). The Breton type (Fig. 1a) is narrow, and possesses a rectangular, thin proximal part with straight flanges and little decoration, sometimes consisting merely of a thin rib under the stopridge. The Breton peninsula is the area where this type is most often found, but it has also been discovered sporadically in Normandy, in the Loire valley and in Burgundy. The Norman type (Fig. 1b) is defined by a trapezoidal blade, a rectangular proximal part with convex flanges, and decoration under the stopridge. Norman palstaves are mostly found in the Lower Seine Valley, to a lesser extent in the Breton peninsula, and also in north-west France, in Burgundy, in Franche-Comté and in southern England (Verney, 1989; Gabillot, 2000, 2003). Such a typological approach is therefore based on the search for one or several discriminant criteria (i.e., overall shape, ornament and detail), intuitively selected with the naked eye, allowing clusters to be identified. Even if this method has been successfully used, it is clear that natural language, including specialized jargon, is inadequate for subtle description, to classify shapes without ambiguity or subjectivity. For this reason a textual description of a shape is usually supplemented by a graphic representation, i.e., in fine, by the shape itself. 


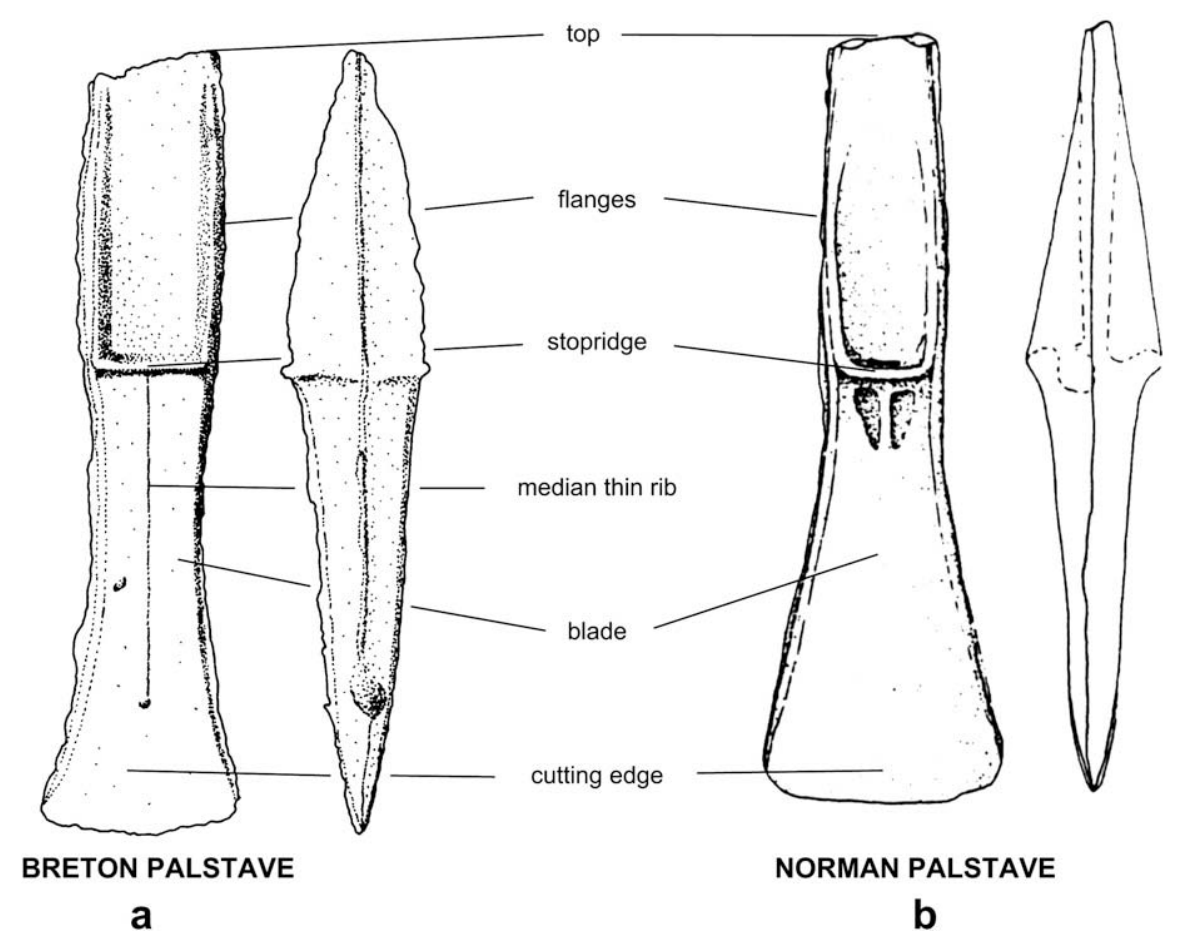

Fig. 1. Principal characteristics of typical Breton (a) and Norman (b) palstaves.

Morphometry (Coster and Chermant, 1989) and statistical shape analyses (Dryden and Mardia, 1998) are frequently used to supplement description in life and earth sciences (e.g., Moellering and Rayner, 1982; Lestrel, 1997; MacLeod, 1999; Navarro et al., 2004; Dommergues et al., 2006), but more rarely in archaeology (e.g., Kendall and Kendall, 1980; Palmqvist et al., 1996; Jerardino and Navarro, 2008). Yet they provide rigorous methods of quantification and analysis, especially when the shape is difficult to define or express. Unlike the naked eye, these methods provide quantification of intra-group variability, which corresponds to shape disparity around the "standard" shape. The aim of the present work is therefore to evaluate the discrimination power of such a morphometrical approach applied to Middle Bronze Age palstaves. First, the morphological space of the Norman and Breton types is defined by applying the Discrete Cosine Transform (Rao and Yip, 1990) to the axe silhouettes. Second, we examine whether the origin of the palstaves excavated at Sermizelles in Burgundy (at least $400-500 \mathrm{~km}$ from conventional production areas, in Normandy and Brittany) can only be explained by importation, as traditionally suggested.

\section{Material and method}

\subsection{Corpus}

The Norman and Breton populations considered in this work are composed of 177 and 203 palstaves dating from the Middle Bronze Age. They come from 61 sites, and 31 sites, all located in the northwest of France (Fig. 2). In addition to these two "standard" populations, 38 palstaves originating from the two contemporaneous hoards of Sermizelles were also studied. Excavated in 1955 in the central-eastern France, the Middle Bronze Age hoards of Sermizelles are sizeable metallic sets, particularly the "Sermizelles II" hoard, which is composed of more than 150 artefacts. There are 68 palstaves in the Sermizelles hoards, of which only 38 are complete: these 38 items were analysed for this study.

\subsection{Choice of a discriminant criterion}

To describe shapes mathematically, one possible approach consists in characterising shapes as configurations of landmarks, thus allowing the visualisation of shape differences via thin-plate spline deformation grids or vector fields (Rohlf and Slice, 1990; Bookstein, 1996; Slice, 2001). Unfortunately, landmarks cannot always be easily defined and located with precision. In any case, such a process could not be straightforwardly applied here because the complete axe silhouettes do not fully correspond to their original shapes. The summit was more or less modified after elimination of the casting cone, whereas the cutting edge may have been drastically reworked due to repetitive sharpening operations, accentuating the curvature by plastic deformation (Gabillot, 2006). It is necessary to find at least one portion of the axe, characteristic of the mould, which has not been altered by the treatments mentioned above. The inner lateral rib presents the advantage of not extending from the heel to the blade, so that it is not affected by the preparation of the axe for use. Unlike the lateral curvature, it has not been modified by polishing or hammering. As a consequence, we found it convenient to apply outline-based morphometrics (e.g., Rohlf and Slice, 1990) to describe the shape of inner lateral ribs.

\subsection{Morphometry}

All inner lateral ribs were drawn by one single operator, using tracing paper, from the available archaeological documentation. Open outlines were individually digitalised at $300 \mathrm{dpi}$. The mathematical method applied to describe these open contours consists of a Discrete Cosine Transform (DCT). Theoretically, such a procedure allows a signal (here the shape of the inner lateral axe rib) to be decomposed into a sum of trigonometric functions, where each harmonic is characterised by its own amplitude. The greater the number of harmonics taken into account, the better the accuracy of the reconstruction process. More details about the fundamentals of this mathematical Fourier-type method (see Appendix), can be 


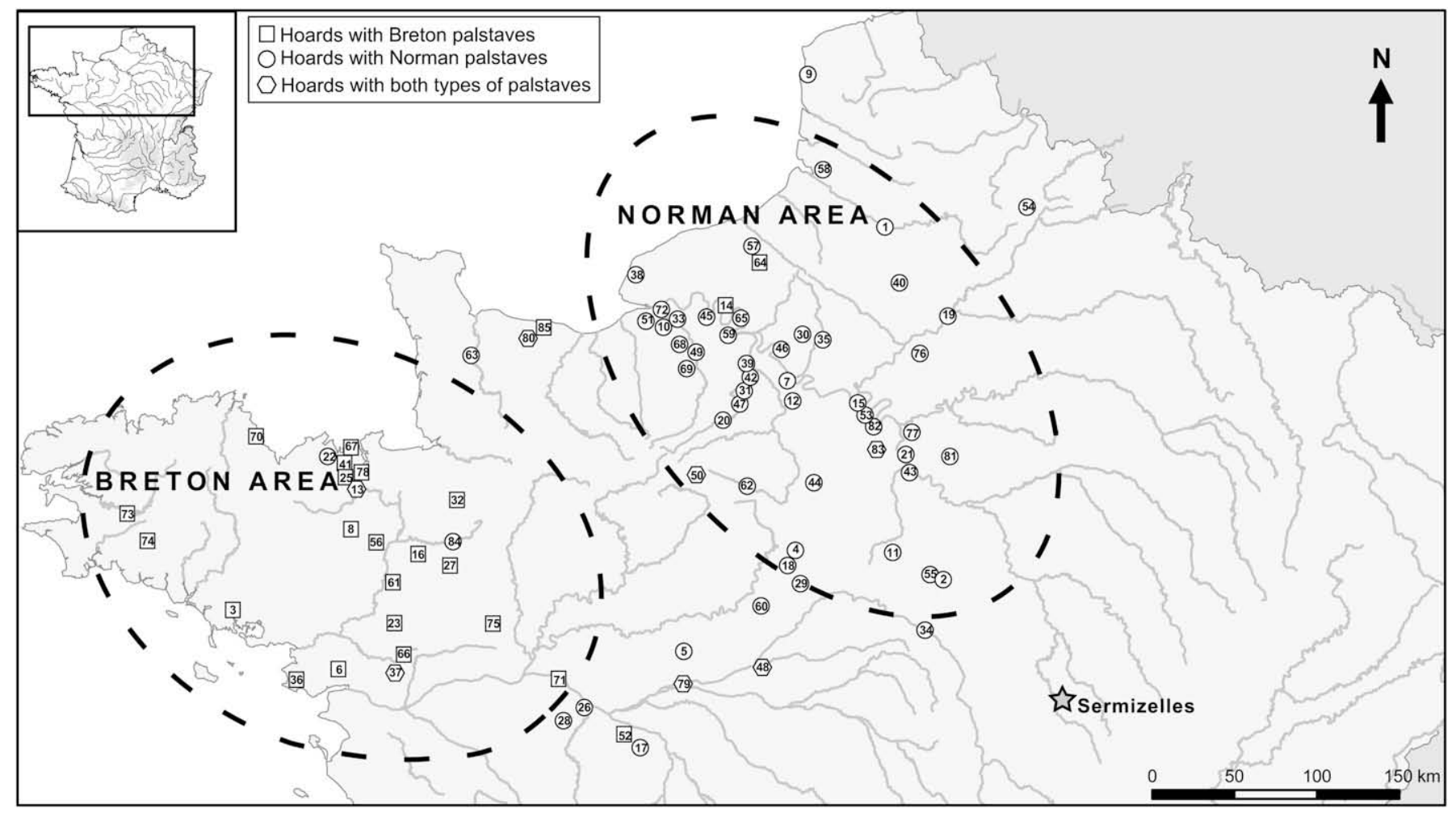

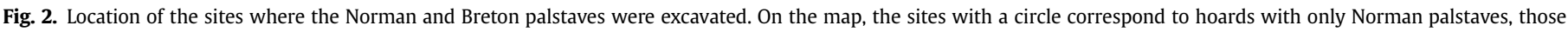

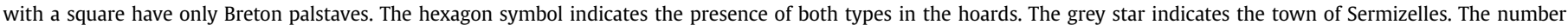

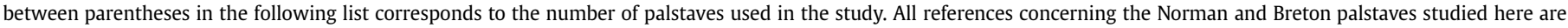

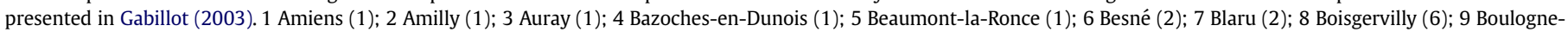

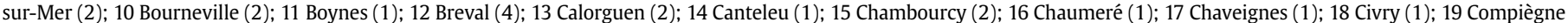

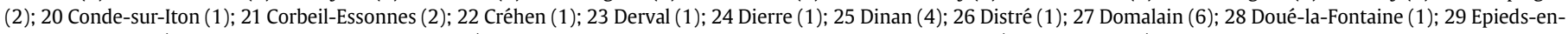

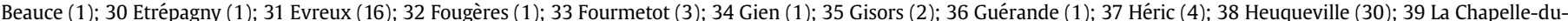

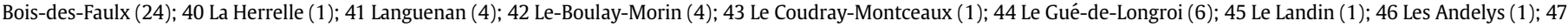

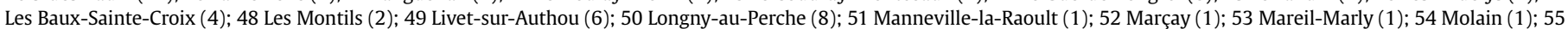

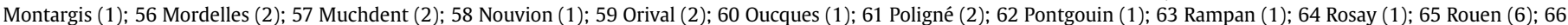

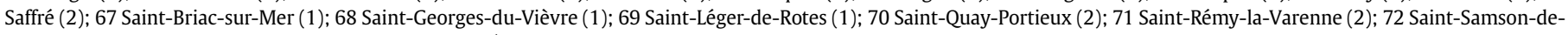

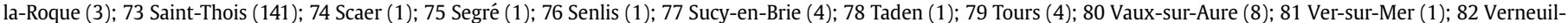
l'Etang (1); 83 Ville-d'Avray (3); 84 Villejust (1); 85 Vitré (2).

found elsewhere (Spaan et al., 1997; Hamarneh and Gustavsson, 2000; Gonzalez and Woods, 2002). A prototype version of the MATLAB toolkit CDFT was used here; it was specially developed by palaeontologists to study ammonite species on the basis of their ribs (Dommergues et al., 2007). In brief, one starting pixel and one end pixel on the curve are selected by the operator. Each rib outline is sampled with 200 uniformly spaced points. The amplitude of the first ten harmonics is then calculated for each palstave (Fig. 3a). Such sampling frequency (and subsequent number of harmonics) is high enough to describe the shape properly (Fig. 3b). The amplitude of the harmonics is then normalised with the chord length of the corresponding rib. This analytical procedure thus produces pure shape descriptors (see Appendix).

\subsection{Possible sources of error}

The operator may introduce errors during three stages: (i) the extraction of the inner lateral rib from the archaeological documentation, (ii) the drawing itself, and (iii) the selection of the starting pixel and end pixel for the DCT calculation. Their influence on the final pattern has to be checked. For verification concerning the first stage, two palstaves (one Norman and one Breton) were selected. Their respective inner lateral ribs were truncated at each extremity to $2.5 \mathrm{~cm}$, with an increment of approximately $3 \mathrm{~mm}$. The profiles were processed as described above. To verify the drawing stage, five inner lateral ribs were drawn twice and treated separately. Finally, 13 profiles were reprocessed using different starting and end pixels.

Statistical analyses (hypothesis tests, discriminant and principal component analyses) were carried out using Statistica 6.1 software for Windows. Bootstrap was performed using a routine developed for MATLAB.

\section{Results and discussion}

\subsection{Discriminating Breton and Norman types}

Palstaves, especially those discovered near the Breton peninsula and the Seine Valley have previously been attributed to Breton and Norman types on the basis of their site of excavation and their morphology, so that both groups are a priori defined. It is therefore possible to check the effectiveness of the information reduction to the inner lateral rib as the sole morphological descriptor by computing a discriminant analysis. This procedure builds a function from available variables, which maximizes the differences between groups, and then allows membership to be assigned to new specimens. The discriminant power of each individual variable can also be evaluated and tested.

Here, the discriminant analysis was computed taking into account the ten harmonic amplitudes produced by the DCT. It is worth mentioning that Kolmogorov-Smirnov tests indicate that all variable distributions for each group do not significantly differ from 

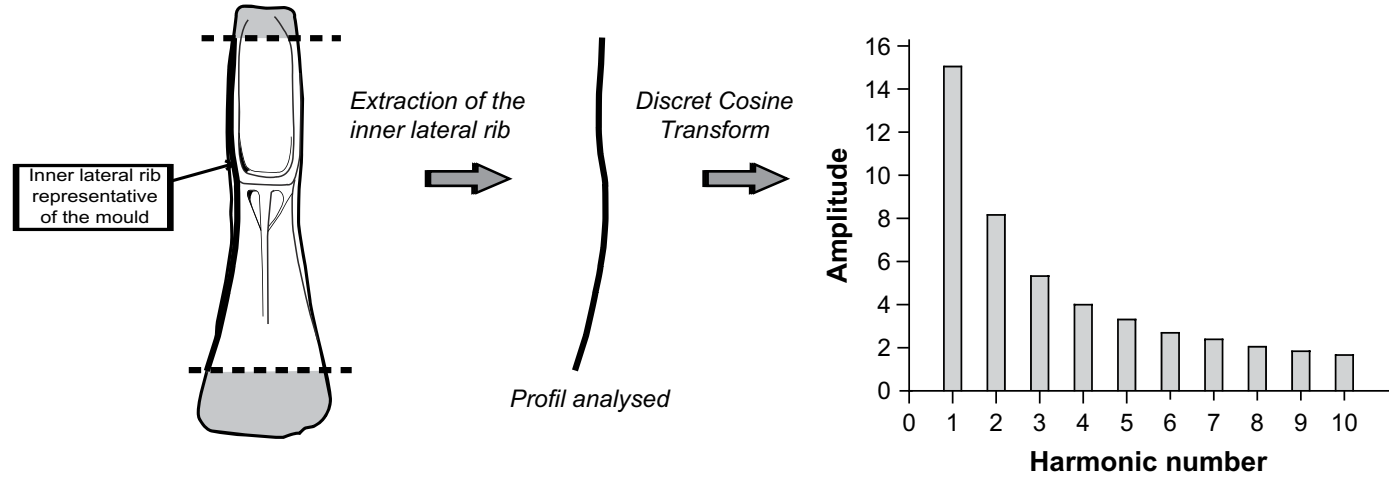

a
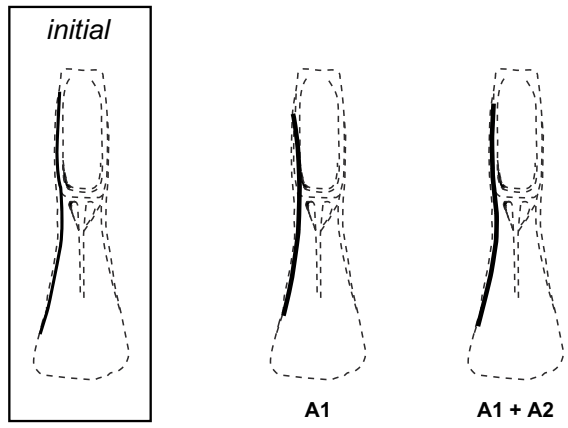

Norman axe
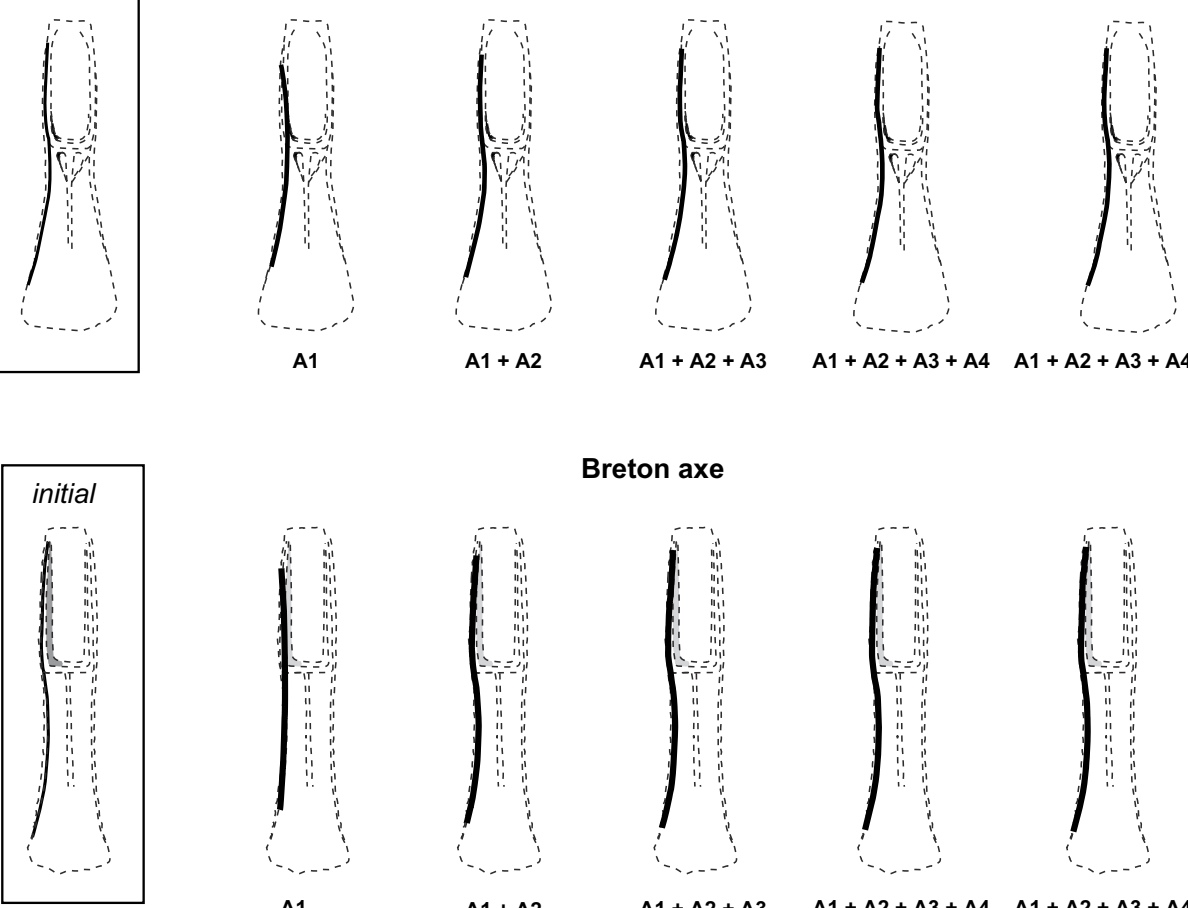

$A 1+A 2+A 3$

$A 1+A 2+A 3+A 4 \quad A 1+A 2+A 3+A 4+A 5$

Breton axe
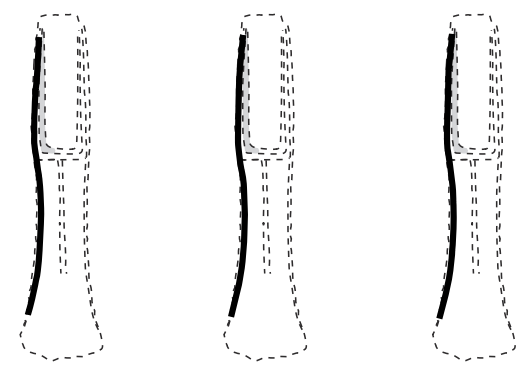

$\mathrm{A} 1+\mathrm{A} 2+\mathrm{A} 3$

$\mathrm{A} 1+\mathrm{A} 2+\mathrm{A} 3+\mathrm{A} 4 \quad \mathrm{~A} 1+\mathrm{A} 2+\mathrm{A} 3+\mathrm{A} 4+\mathrm{A} 5$

b

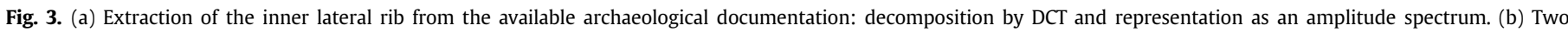
examples of quality reconstitution improvement when increasing the number of harmonics taken into account.

normal, which constitutes an ideal situation for running this statistical procedure. A test of significance on the Mahalanobis distance, which corresponds to the square of the Euclidean distance between centroids of each group (Legendre and Legendre, 1998), demonstrates that the DCT values of the inner lateral ribs can be used to discriminate very efficiently between Norman and Breton types $(F=47.66, p<0.001)$. Only the first seven harmonics appear to be useful for the analysis, and their power decreases with their rank (not shown here). The other harmonics probably represent random effects, noise due to imprecision in drawing, or were induced during digitalisation. Distributions of resulting scores have a non-null intersection (Fig. 4), but approximately 87\% of Breton and $81 \%$ of Norman axes are well sorted. Cohen's Kappa coefficient, which is a statistical measure of "inter-rater" agreement, was used to evaluate the concordance between the typology previously established by archaeologists, and the discriminant analysis. It appears that $\kappa=0.67 \pm 0.03(1 \sigma)$. Such a value corresponds to a substantial agreement $(p<0.05)$ as proposed by Landis and Koch (1977). As a consequence, the reduction from the overall axe features to the inner lateral rib seems to be a pertinent choice.

\subsection{Evaluation of the robustness of the procedure}

The position of Breton and Norman groups can be illustrated using exploratory representations produced by Principal Component Analysis (PCA). However, as all harmonics possess the same unit, but not the same magnitude and the same meaning, we chose to perform the PCA using a covariance matrix instead of 

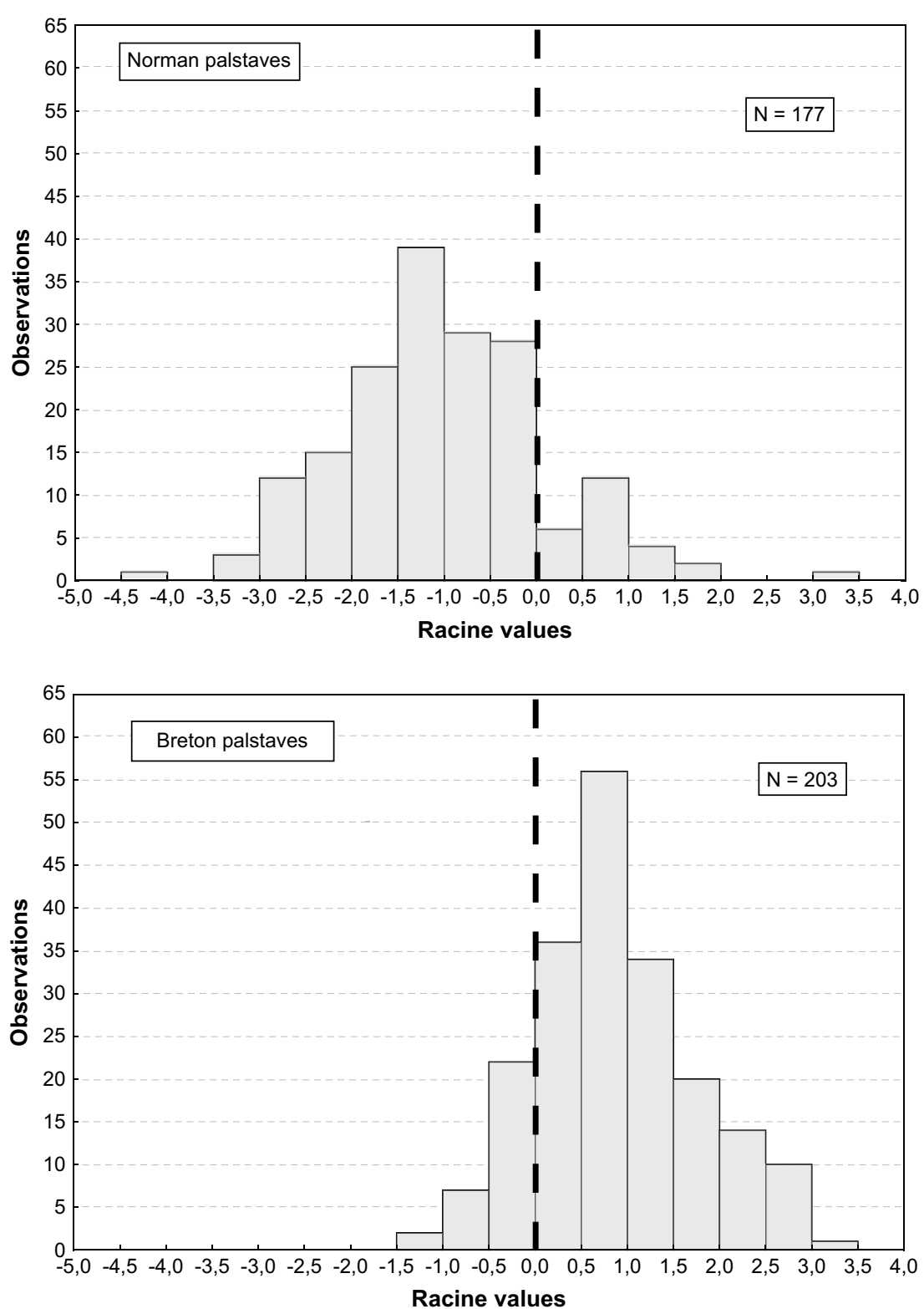

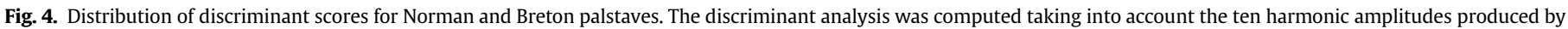
the DCT for the 177 Norman palstaves and the 203 Breton palstaves. The threshold was voluntarily set at the origin.

a correlation matrix, in order not to give too much weight to high harmonics, which account for less variance than the first harmonics (Lestrel, 1997). That is why the use of a covariance matrix on the morphological space pre-processed by the DCT is well adapted for the visualisation. Only the first seven harmonics were processed, as they had previously been identified as presenting significant discrimination power. Most of the variance is depicted with a single 2D diagram, since the first and second factors contribute $86.63 \%$ and $9.75 \%$ to the total variance, respectively (Fig. 5a and b). The F1 factor is governed at $99.5 \%$ by the first harmonic, while the second harmonic predominates ( $88 \%$ ) on the $\mathrm{F} 2$ factor. The overall position of the Breton and Norman groups well illustrates the differences already identified by the discriminant analysis.

When the truncated profiles of the two palstaves are projected into the morphological space (Fig. $6 a$ and b), the dots cover a large range, essentially along the first factor. Although such variations are considerable, it must be kept in mind that this situation is quite artificial and surpasses any mistakes that an operator could reasonably make, as it corresponds to an elimination of almost $2.5 \mathrm{~cm}$ at each extremity of the inner lateral rib. More realistically, actual error should not exceed one third or one fourth of the domain displayed in the diagrams. In the same way, the reproducibility concerning the drawing itself and the selection of the starting pixel and end pixel for DCT calculation is illustrated in Fig. $6 \mathrm{c}$ and $\mathrm{d}$ respectively. Both types of errors are comparable and are very low with respect to intra- and inter-group variability. As a result, the greatest source of errors clearly derives from the extraction of the inner lateral rib from the archaeological documentation, but the overall structure of the morphological space should be not drastically altered.

\subsection{Case of the hoards of Sermizelles}

As mentioned above, the palstaves of Sermizelles were previously attributed either to the Norman or to the Breton types. If these two types alone were present, the discriminant analysis could 

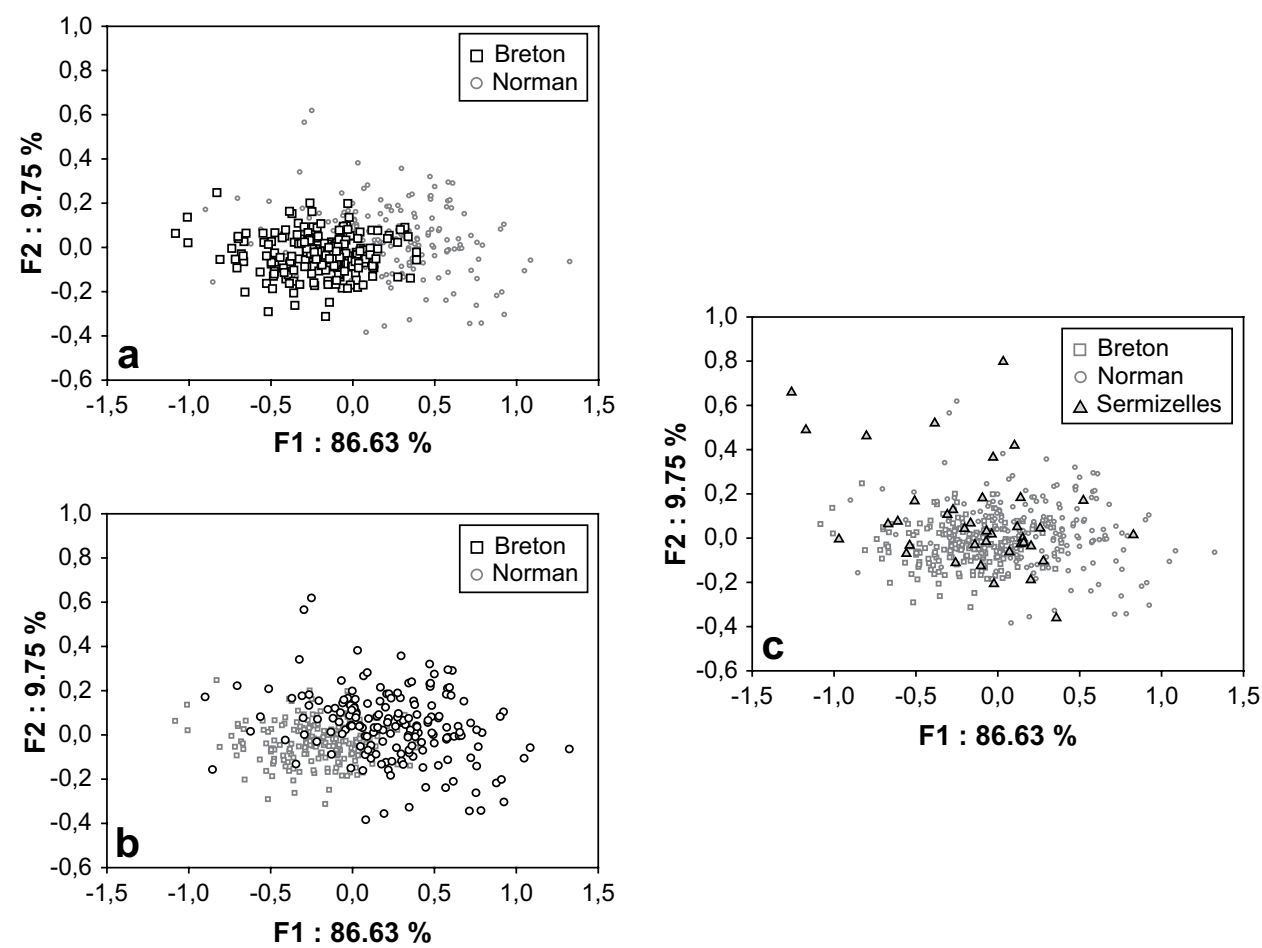

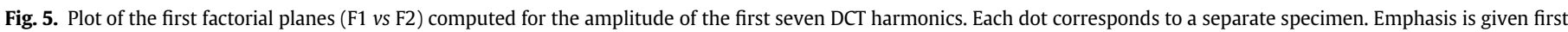

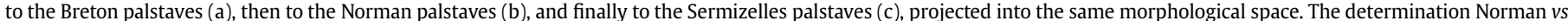

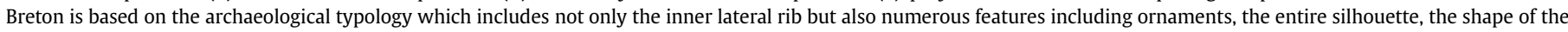
stopridge, etc. Within a given group, variants exist and produce morphological disparity.

be used to classify these palstaves: the Breton type would represent $68 \%$ of the whole set, while the remainder would obviously belong to the Norman group. After projection into the morphological space (Fig. 5c), half of the Sermizelles specimens plot in the vicinity of both the Norman and the Breton centroids and/or close to their intersection. However Sermizelles palstaves display a wide disparity of shapes with many individuals, spreading out to the edge of the main body or even outside. This tends to complicate the binary origin hypothesis.

It is therefore interesting to evaluate and compare the shape disparity of the Norman type, the Breton type, and the whole Sermizelles set, using disparity indices such as total variance and total range. Since the sum of ranges is a disparity measure which depends on the sample size, a rarefaction procedure is applied. This bootstrapping approach compensates the differences in sample size when comparing populations, by computing the sum of ranges for repeatedly pulled random subsamples of decreasing size.

These approaches to assess morphological disparity have firm grounding in bio-geosciences, and more details about these routinely used procedures, especially with bootstrap, can be found in an abundant literature (e.g., Foote, 1991, 1992, 1993; Wills, 2001). Here, even if comparisons between Norman and Breton types are straightforward because both sets contain approximately the same number of artefacts $(\sim 200)$, a rarefaction procedure is necessary to compare them with Sermizelles, which contains only 38 axes, since range-based estimates of disparity are sample-size dependent (Foote, 1992). Shape disparity, expressed as total range (Fig. 7a), and variance (not shown here) are significantly greater for the Norman than for the Breton type. It is important to recall that all these palstaves are contemporaneous and produced in neighbouring areas. The shape disparity of the Sermizelles hoards is higher than that of Norman and Breton types taken separately (Fig. 7a). But such a finding might be quite compatible with an assortment of axes from these two groups. To test this hypothesis, the Breton and Norman groups were pooled (Fig. 7b). The shape disparity of this new pool still appears lower than that of Sermizelles $(p<0.001)$, in terms of both range (Fig. 7b), and variance (not shown here).

\section{Archaeological interpretation}

The mathematical treatment of the inner lateral rib fits well with the typology previously established by archaeologists (see Cohen's kappa). Around 1500 B.C., the metallic production was well controlled and rather homogeneous in terms of shape, necessarily implying a certain standardisation within each of the two cultural groups. This suggests that the conscientiousness of metalworkers belonging to a given society might be expressed by the stability in shape of the artefacts they produced; such shapes being typical of their culture. The present approach, however, offers new opportunities to better understand the metallurgical practices in northwestern France during the Middle Bronze Age. As mentioned above, the Breton palstaves exhibit lower shape diversity than the Norman type. Such a distinction between the situation in the Breton peninsula and in the Lower Seine Valley has already been noticed in other circumstances: (i) ore deposits are abundant in Brittany, while they are virtually nonexistent in Normandy (Geological map of France, BRGM); (ii) the post-casting treatment of the palstaves is clearly different from one area to another (Gabillot, 2004); (iii) the hoards are different in terms of size and composition (Gabillot, 2003). All these clues, including shape disparity, plead for major differences concerning the control of metallic production within the two cultural areas.

The introduction into the analysis of Sermizelles palstaves, discovered far from the presumed production areas, provides information about the circulation of metallic artefacts. This set of palstaves cannot be explained by a simple assortment involving Breton and Norman sources only. It is unlikely that the atypical 

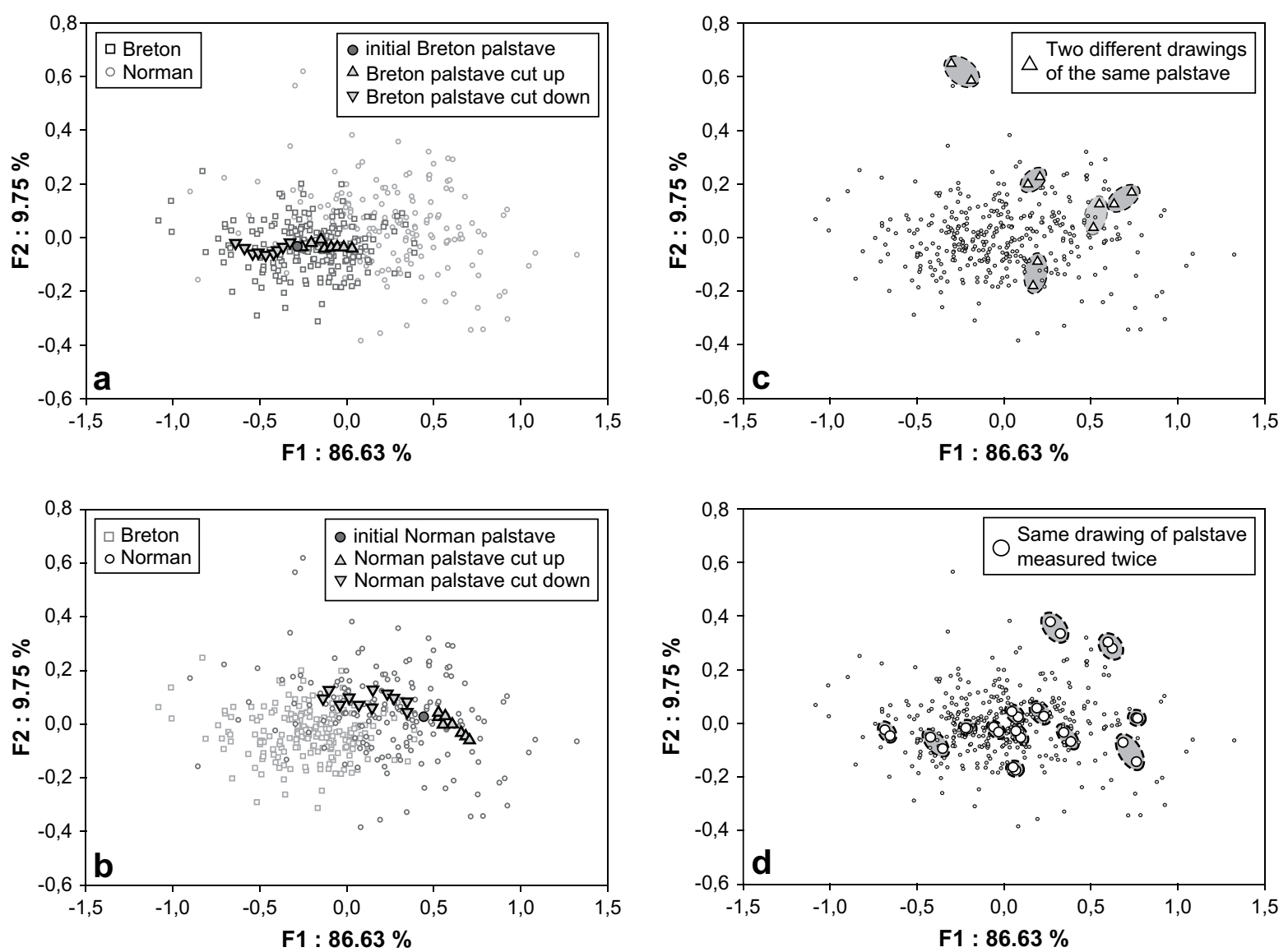

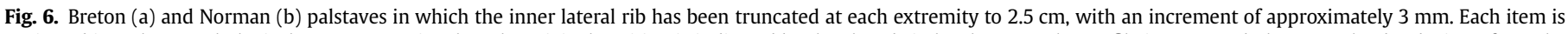

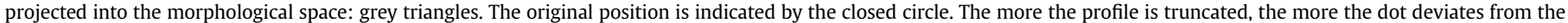

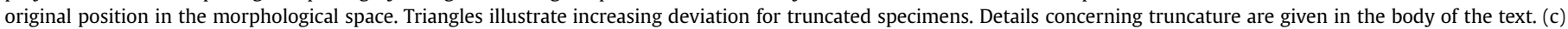

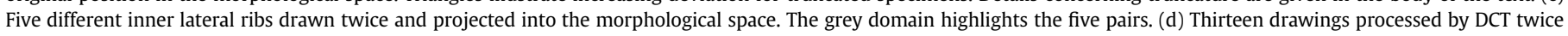
(different choices concerning the starting pixel and end pixel) and projected into the morphological space. The grey domain highlights the thirteen pairs.

palstaves found in the Sermizelles hoard really correspond to shapes which had not been recognized in the production areas, because the corpus used here is large enough to be considered as fully representative (almost 400 palstaves). The best hypothesis is therefore that one or more other sources were involved. Because of their overall likeness to the Norman and Breton types, these palstaves could be imitations of the "standard" models. Even if their production areas are still unknown, it is worth mentioning that the site of Sermizelles is situated just north of the Morvan massif, where indirect evidence of mining and metallurgical activities during the Bronze Age has already been recognized (Monna et al., 2004; Jouffroy-Bapicot et al., 2007). In any case, beyond the traditional diffusion of artefacts from the mass production areas, the present study suggests an immaterial circulation of ideas and know-how. Many minor centres of Norman- and Breton-like palstaves may have existed outside the presumed limits of production areas.
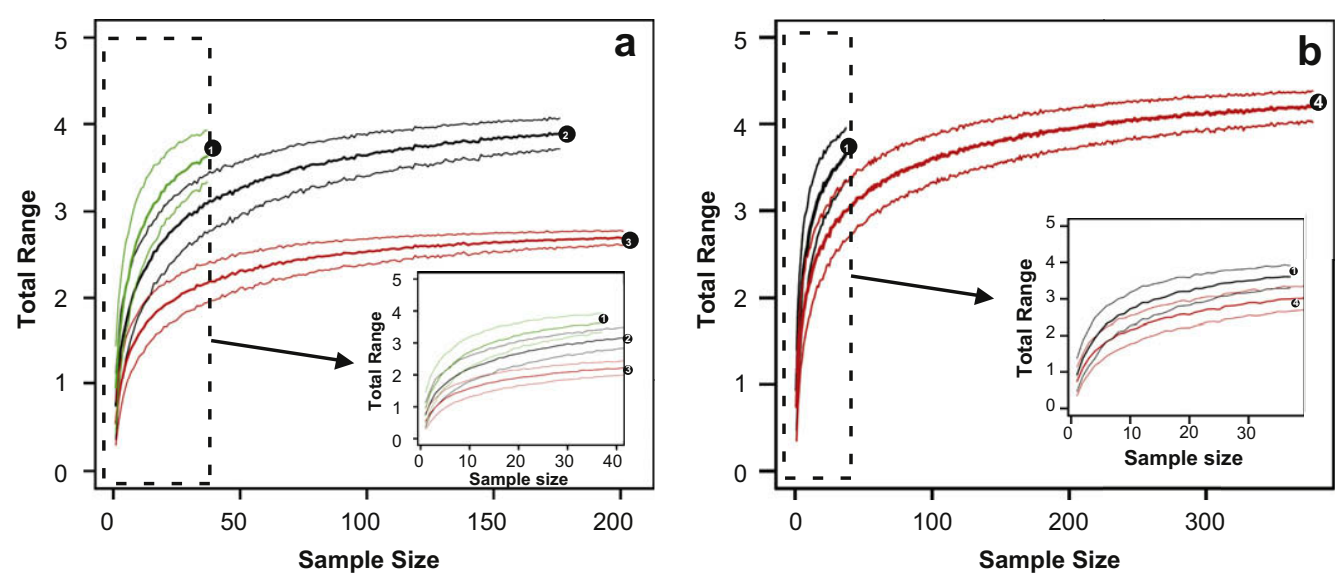

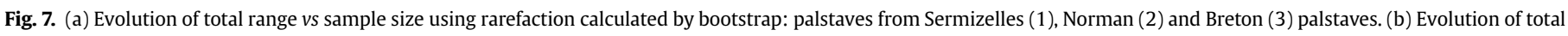
range vs sample size using rarefaction calculated by bootstrap: palstaves from Sermizelles (1), and Norman and Breton pooled (4). 


\section{Conclusion}

The mathematical processing of the inner lateral rib is useful to discriminate Norman and Breton palstaves, and complements the traditional typology. This feature is easily accessible and can be extracted without major problems from the available archaeological documentation. In spite of the absence of easily identifiable landmarks, requiring the use of outline-based approaches, the Discrete Cosine Transform appears to be an appropriate tool for analyzing open contours, since the procedure is costless, quick, simple, precise and reproducible. The morphometric approach allows the construction of a morphological space which valuably illustrates the most frequent shape, in other words the central tendency, and also the spread of individuals around this "standard" morphology. This shape disparity could not have been evaluated by naked-eye observations alone, yet it is an important descriptor for these populations. With a Principal Component Analysis, the morphology of more than 400 samples was graphically represented using one single diagram, without constantly having to refer back to the original drawings. This methodology constitutes a convenient tool for further studies focusing on palstaves, because it makes comparisons between populations much easier. Moreover, this quantification enables the use of statistical tests that are a considerable improvement on the traditional typology. In the example presented here, only the inner lateral rib was taken into account, but we can easily imagine that it could be supplemented by other features such as chemical or isotopic composition. The nature of exchanges taking place during the Middle Bronze Age could be better understood by extending the procedure to other European hoards and by spatialising the information. For instance, it would be interesting to check if the presence of outliers increases as we move away from the traditional production areas. More generally, the method can easily be applied to other archaeological artefacts such as fibulas, metallic vessels or ceramics.

\section{Acknowledgments}

We wish to thank Jean-Louis Dommergues for his help with the study and for his comments on the manuscript, and Claude Sestier, recently deceased, for the discussions about this subject. We are grateful to the anonymous reviewer whose judicious comments improved the manuscript. We also wish to thank the Regional Council of Burgundy and the CNRS for their support, and funding for the PhD thesis of Benoit Forel (CNRS BDI-R 2004.3 Bourgogne), as well as the ACR program, directed by Jean-François Piningre, about the study of Bronze Age in eastern France.

\section{Appendix}

Among an infinite number of possible decompositions, the Discrete Cosine Transform (Rao and Yip, 1990), because of its effectiveness and its ease of implementation, has become the base for a whole generation of lossy compression standards such as JPEG, MPEG-2, MP3, etc... In particular, a continuous aperiodic signal is not degraded by the Gibbs phenomenon when compressed with DCT. This interference is typical of Fourier's transforms when applied to discontinuous or aperiodic signals. As soon as some harmonics are removed, some ripples, centered on the discontinuities, occur on the reconstructed signal (Dommergues et al., 2007). A transform such as the Discrete Fourier Transform (DFT) apprehends all signals as periodic, so, if the original signal is aperiodic, the DFT will implicitly introduce periodical discontinuities. In comparison, performing a DCT is similar to applying a DFT on a (always) periodic signal carried out by symmetry duplication of the original signal (Gonzalez and Woods, 2002). Hence, the DCT is a suitable tool to quantify and compare open (i.e., aperiodic) contours and is especially useful when landmarks are difficult to define or localise. The shapes must be similar, the Nyquist-Shannon sampling theorem must be respected, and the number of samples must be identical for each specimen (Gonzalez and Woods, 2002). A two-dimensional curve can be represented by a complex-valued analog signal $s(t)$,

$s(t)=x(t)+i y(t), \quad 0 \leq t<T$

where variable $t$ is the curvilinear abscissa, $T$ is the curve length, and parametric functions $x$ and $y$ are Cartesian coordinates along the curve. If $N$ is the number of samples, then the sampling rate is equal to $1 / \Delta T$ with $\Delta T=T /(N-1)$. The discrete signal $s[n]$ can be expressed as:

$s[n]=s(n \Delta T), \quad \Delta T=T /(N-1), \quad n=0,1, \ldots, N-1$

The forward DCT of $s[n]$ is given by:

$S[k]=\sum_{n=0}^{N-1} c[k] s[n] \cos \left(\frac{(2 n+1) k \pi}{2 N}\right), \quad k \in \mathbb{Z}$

and the corresponding inverse DFT is given by:

$s[n]=\sum_{k=0}^{N-1} c[k] S[k] \cos \left(\frac{(2 n+1) k \pi}{2 N}\right), \quad n \in \mathbb{Z}$

where

$c[k]= \begin{cases}\frac{1}{\sqrt{N}}, & k=0 \\ \sqrt{\frac{2}{N}}, & k \neq 0\end{cases}$

Equation (4) exhibits the harmonic decomposition of $s[n]$, which is the sum of $N$ cosine functions weighted by the Fourier coefficients $S[k]$. These are complex-valued, and so can be expressed in polar form to provide two real-valued spectra: the amplitude spectrum and the phase angle spectrum. The first Fourier coefficient $S[0]$ is a constant corresponding to the centroid of the samples. Except for this coefficient, which is obviously translation-dependent, the amplitudes are invariant to translations and rotations. By standardising the size, they become a good proxy for morphology.

\section{References}

Bookstein, F.L., 1996. Landmark methods for forms without landmarks: morphometrics of group differences in outline shape. Medical Image Analysis 1 (3), 225-243.

Briard, J., Verron, G., 1976. Typologie des objets de l'âge du Bronze en France, III: Haches (1), IV: Haches (2), herminettes. Société Préhistorique Française, Commission du Bronze, Paris.

Briard, J., Bigot, B., 1989. Le bronze atlantique: de Tréboul aux haches à talon en Armorique in: Actes du 113ème Congrès des Sociétés Savantes, La culture des tumulus et la dynamique du Bronze moyen en Europe occidentale. Editions du Comité des Travaux Historiques et Scientifiques, Paris, pp. 523-536.

Coster, M., Chermant, J.L., 1989. Précis d'analyse d'image. Editions CNRS, Paris.

Dommergues, J.L., Dommergues, C.H., Meister, C., 2006. Exploration of the Oxynoticeratidae ornemental morphospace using the discrete cosine transform (DCT) to analyze rib patterns. Paleobiology 32 (4), 628-651.

Dommergues, C.H., Dommergues, J.L., Verrecchia, E.P., 2007. The Discrete Cosine Transform, a Fourier-related method for morphometric analysis of open contours. Mathematical Geology 33 (8), 749-763.

Dryden, I.L., Mardia, K.V., 1998. Statistical Shape Analysis, first ed. John Wiley \& Sons Ltd.

Foote, M., 1991. Analysis of morphological data. In: Gilinsky, N.L., Signor, P.W. (Eds.), Analytical Paleobiology. The Paleontological Society, Knoxville, pp. 59-86.

Foote, M., 1992. Rarefaction analysis of morphological and taxonomic diversity. Paleobiology 18, 1-16.

Foote, M., 1993. Discordance and concordance between morphological and taxonomic diversity. Paleobiology 19, 185-204.

Gabillot, M., 2000. Les dépôts complexes de la fin du Bronze moyen et du début du Bronze final en France du Centre-Est. Nouvelle approche. Bulletin de la Société Préhistorique Française 97 (3), 459-476.

Gabillot, M., 2003. Dépôts et production métallique du Bronze moyen en France nord-occidentale. In: British Archaeological Reports. International Series, vol. 1174,471 p. 
Gabillot, M., 2004. La fragmentation des objets: critère d'étude des dépôts de l'âge du Bronze in: Actes du 25ème Congrès Préhistorique de France, Approches fonctionnelles en Préhistoire, Nanterre, novembre 2000, pp. 1-9.

Gabillot, M., 2006. Les manipulations après la fonte des objets en alliage cuivreux: caractéristique sociale, économique et culturelle? L'exemple des haches à talon du Bronze moyen du Nord-Ouest français. In: Astruc, L., Bon, F., Léa, V., Milcent, P.Y., Philibert, S. (Eds.), Normes Techniques et Pratiques sociales. De la simplicité des outillages pré- et protohistoriques. XXVIe rencontres internationales d'archéologie et d'histoire d'Antibes. Editions APDCA, Antibes, pp. 287-296.

Gabillot, M., Gomez de Soto, J., 2007. Trésors et cachettes de l'âge du Bronze en France: cent ans de recherches et d'évolution des méthodes d'analyse in: Actes du 26ème Congrès Préhistorique de France, Centenaire de la Société préhistorique française, Avignon-Bonnieux, septembre 2004, pp. 55-69.

Gonzalez, R.C., Woods, R.E., 2002. Digital Image Processing, second ed. PrenticeHall, Upper Saddle River.

Hamarneh, G., Gustavsson, T., 2000. Combining snakes and active shape models for segmenting the humanleft ventricle in echocardiographic images. Computers in Cardiology, 115-118.

Harding, A.F., 2000. European Societies in the Bronze Age, first ed. Cambridge University Press.

Jerardino, A., Navarro, R., 2008. Shell morphometry of seven limpet species from coastal shell middens in southern Africa. Journal of Archaeological Science 35, 1023-1029.

Jouffroy-Bapicot, I., Pulido, M., Baron, S., Galop, D., Monna, F., Lavoie, M., Petit, C. de Beaulieu, J.-L., Richard, H., 2007. Environmental impact of early palaeometallurgy: pollen and geochemical analysis. Vegetation History and Archaeobotany 16, 251-258.

Kendall, D.G., Kendall, W.S., 1980. Alignments in two dimensional random set of points. Advances in Applied Probability 12, 380-424.

Landis, J.R., Koch, G.G., 1977. The measurement of observer agreement for categorical data. Biometrics 33, 159-174.

Legendre, P., Legendre, L., 1998. Numerical Ecology. Elsevier, Amsterdam.

Lestrel, P.E., 1997. Fourier Descriptors and Their Applications in Biology, first ed. Cambridge University press.

MacLeod, N., 1999. Generalizing and extending the eigenshape method of shape space visualization and analysis. Paleobiology 25 (1), 107-138.

Millotte, J.P., 1989. Les dépôts ou cachettes de l'âge du Bronze Moyen en France: état de la question in: Actes du 113ème Congrès des Sociétés Savantes, La culture des tumulus et la dynamique du Bronze moyen en Europe occidentale. Editions du Comité des Travaux Historiques et Scientifiques, Paris, pp. 539-543. cartographic forms. The Cartographic Journal 19 (1), 53-59.

Monna, F., Petit, C., Guillaumet, J.-P., Jouffroy-Bapicot, I., Blanchot, C., Dominik, J., Losno, R., Richard, H., Lévêque, J., Chateau, C., 2004. History and environmental impact of mining activity in Celtic Aeduan territory recorded in a peat-bog (Morvan - France). Environmental Science \& Technology 38 (3), 665-673.

Mordant, C., 1998. Dépôts de bronzes et territoires à l'âge du Bronze en Bourgogne (XVII-IXe siècle avant J.-C.). In: Mordant, C., Pernot, M., Rychner, V. (Eds.), L'atelier du bronzier en Europe du XXe au VIIIe siècle avant notre ère. T.3 Production, circulation et consummation du bronze. Editions du Comité des Travaux Historiques et Scientifiques, Paris, pp. 185-210.

Navarro, N., Zatarain, X., Montuire, S., 2004. Effects of morphometric descriptor changes on statistical classification and morphospaces. Biological Journal of the Linnean Society 83 (2), 243-260.

Needham, S.P., 1998. Modelling the flow of metal in the Bronze Age. In: Mordant, C., Pernot, M., Rychner, V. (Eds.), L'atelier du bronzier en Europe du XXe au VIIIe siècle avant notre ère. T.3 Production, circulation et consummation du bronze. Editions du Comité des Travaux Historiques et Scientifiques, Paris, pp. 285-307.

Palmqvist, P., Pérez-Claros, J.A., Gibert, J., Santamaria, J.L., 1996. Comparative morphometric study of a human phalanx from the lower Pleistocene site at Cueva Victoria (Murcia, Spain), by means of Fourier analysis, shape coordinates of landmarks, principal and relative warps. Journal of Archaeological Science 23, 95-107.

Pare, C., 2000. The Bronze and the Bronze Age. In: Pare, C. (Ed.), Metals make the World go Round. Oxbow Books, Oxford, pp. 1-38.

Rao, K., Yip, P., 1990. Discrete Cosine Transform: Algorithms, Advantages, Applications. Academic Press, Boston.

Rohlf, F., Slice, D., 1990. Extensions of the procrustes method for the optimal superimposition of landmarks. Systematic Zoology 39 (1), 40-59.

Spaan, F.H.P., Lagendijk, R.L., Biermond, J., 1997. Shape coding using polar coordinates and the discrete cosine transform. In: 1997 International Conference on Image Processing (ICIP'97). vol. 1, pp. 516-519.

Slice, D.E., 2001. Landmark coordinates aligned by procrustes analysis do not lie in Kendall's shape space. Systematic Biology 50 (1), 141-149.

Verney, A., 1989. La place des haches à talon de type normand dans l'étude du Bronze moyen en France in: Actes du 113ème Congrès des Sociétés Savantes, La culture des tumulus et la dynamique du Bronze moyen en Europe occidentale. Editions du Comité des Travaux Historiques et Scientifiques, Paris. 479-489.

Wills, M.A., 2001. Disparity vs. diversity. In: Briggs, D.E.G., Crowther, P.R. (Eds.), Paleobiology II. Blackwell Publishing, Malden, pp. 495-500. 